\title{
INFLUÊNCIA DA UMIDADE DO BAGAÇO DA CANA-DE-AÇÚCAR NO SISTEMA DE COGERAÇÃ̃O DE ENERGIA
}

\section{INFLUENCE OF THE HUMIDITY OF SUGAR CANE BAGGAGE IN THE ENERGY COGENERATION SYSTEM}

\author{
Alan Henrique Souza Carvalho ${ }^{\mathrm{I}}$ \\ Carlos Alexandre dos Santos ${ }^{\text {II }}$ \\ Solange Pereira dos Santos Farah ${ }^{\mathrm{III}}$ \\ Alessandro Fraga Farah ${ }^{\text {IV }}$
}

\begin{abstract}
RESUMO
Este trabalho apresenta um estudo de caso das variáveis de processo em uma caldeira de uma termoelétrica, na qual se avalia a as principais perdas energéticas de natureza térmica, bem como seu impacto na cogeração de energia. Procurou-se conhecer as principais causas de perda de eficiência durante o processo de geração de energia em usinas sucroalcooleiras. Para realização deste estudo fez-se uma pesquisa de campo numa indústria do ramo sucroenergético situada no interior do estado de São Paulo, tendo como principais atividades a industrialização de açúcar, álcool e cogeração de energia. Foram analisados dados de uma caldeira industrial cuja umidade encontrada no bagaço da cana-de-açúcar é variável e, portanto, causa uma combustão irregular, impactando na variação da relação de troca térmica na queima e consequentemente, na ineficiência da cogeração. A empresa tem como meta manter a umidade do bagaço em 50\% para manter a eficiência energética da caldeira, diante desse contexto, o trabalho teve como objetivo apresentar a relação direta entre a umidade do bagaço e a eficiência energética de produção na cogeração. Os resultados encontrados mostram que as medidas de controle e análise do bagaço final das moendas é de extrema importância, uma vez que há uma relação inversa entre a umidade e eficiência energética, ou seja, o aumento da umidade acarreta uma perda de eficiência na produção de vapor, e consequentemente na produção de energia.
\end{abstract}

Palavras-chave: Estatística. Energia renovável. Caldeira termoelétrica.

\begin{abstract}
This work presents a case study of the process variables in a boiler of a thermoelectric plant, in which the main thermal losses of thermal nature, as well as their impact on the energy cogeneration, are evaluated. The main causes of loss of efficiency during the process of power generation in sugar and alcohol plants were investigated. In order to carry out this study, a field research was carried out in a sugarcane industry located in the interior of the state of São Paulo, whose main activities are the industrialization of sugar, alcohol and energy cogeneration. Data from an industrial boiler whose moisture found in the sugarcane bagasse is variable, and thus

' Estudante do Curso Superior de Tecnologia em Manutenção Industrial da Faculdade de Tecnologia (FATEC) de Sertãozinho - São Paulo - Brasil. E-mail: carvalhoalan14@gmail.com

II Estudante do Curso Superior de Tecnologia em Manutenção Industrial da Faculdade de Tecnologia (FATEC) de Sertãozinho - São Paulo - Brasil. E-mail: carlos.alexandre@sp.senai.br

IIIProfa. Me. da Faculdade de Tecnologia (FATEC) de Sertãozinho - São Paulo - Brasil. E-mail: solange.farah@fatec.sp.gov.br

${ }^{\text {IV} P r o f . ~ D r . ~ d a ~ F a c u l d a d e ~ d e ~ T e c n o l o g i a ~(F A T E C) ~ d e ~ S e r t a ̃ o z i n h o ~-~ S a ̃ o ~ P a u l o ~-~ B r a s i l . ~ E-m a i l: ~}$ alessandro.farah@fatec.sp.gov.br
\end{abstract}


causes an irregular combustion, impacting on the variation of the thermal exchange ratio in the burning and, consequently, on the inefficiency of the cogeneration. The company aims to maintain the moisture content of the bagasse by $50 \%$ in order to maintain the energy efficiency of the boiler. In this context, the objective of this work was to present the direct relationship between bagasse moisture and cogeneration production energy efficiency. The results show that the measures of control and analysis of the final bagasse of the mills is of extreme importance, since there is an inverse relation between the humidity and energy efficiency, that is, the increase of humidity entails a loss of efficiency in the production of steam, and consequently in energy production.

Keywords: Statistic. Renewable energy. Thermoelectric Boiler.

Data de submissão do artigo: 22/05/2019.

Data de aprovação do artigo: 03/07/2019.

DOI:

\section{INTRODUÇÃO}

Os sistemas de cogeração, que permitem produzir simultaneamente energia elétrica, e calor útil, configuram a tecnologia mais racional para a utilização de combustíveis, embora sejam viáveis apenas nos contextos onde se demandam ambas as formas de energia. Este é o caso das indústrias sucroenergéticas e de papel e celulose, que além de demandar potência elétrica e térmica, dispõem de combustíveis residuais que se integram de modo favorável ao processo de cogeração (COMIN, 2010). Hoje se considera que uma usina deve obter toda a sua energia pela combustão do bagaço da cana-de-açúcar e que também gere excedentes energéticos que transformado em energia elétrica é vendida para a concessionária de eletricidade.

O bagaço, que antes era um problema aos produtores pela difícil armazenagem e quase nenhuma utilização, agora surge como fonte natural de energia. A umidade do bagaço da canade-açúcar influência de maneira significativa em fatores que afetam diretamente na eficiência da produção de energia. Ela está diretamente ligada ao consumo do combustível, produção de vapor e consequentemente, na geração de energia elétrica. Sabe-se que quanto mais úmido estiver o bagaço maior será seu consumo para a produção de vapor (NOVA CANA, 2013). Outros fatores podem influenciar no poder calorífico, como os açúcares não extraídos pela moenda, ainda presentes nas fibras do bagaço, e o tipo de consumo, quando consumido diretamente, ou estocados em montes, sujeitos as intempéries e a fermentação pelo tempo.

O sistema de cogeração em estudo trabalha com uma caldeira aquatubular com capacidade máxima de produção de 135 toneladas de vapor/hora. A caldeira recebe o bagaço do estoque do pátio, juntamente como restante proveniente da moenda. Eles são transportados por meio de esteiras até os dosadores e os mesmos insuflam o bagaço para dentro da caldeira. Dessa forma por meio de ventiladores e exaustores o bagaço deve queimar em suspensão, proporcionando uma queima uniforme em todo grelhado. Quando ele apresenta uma umidade acima de 50\%, possuiu uma dificuldade maior na eficiência de queima. O bagaço úmido se acumula no grelhado causando a depressão positiva de fornalha, pois a caldeira começa a secar o bagaço antes, para depois queimá-lo.

O objetivo deste estudo foi verificar o quanto a umidade interfere no poder calorífico do bagaço, impactando diretamente no resultado da cogeração de energia elétrica. 


\section{SETOR SUCROENERGÉTICO}

De acordo com a revista Nova Cana (2013), a produção de cana no Brasil cresceu de forma acelerada após o estabelecimento do Proálcool, em 1975, passando de um patamar de pouco menos de 100 milhões de t/ano para 220 milhões de t/ano, em 1986/87. O cultivo da cana só voltou a crescer na safra 93/94, desta vez, motivado pelo aumento das exportações de açúcar. A partir daí o crescimento da produção tem ocorrido de forma contínua (com exceção do período entre 1998 a 2001, quando houve uma queda gerada pela crise no setor). Com o sucesso dos veículos flex, lançados em 2003, a produção voltou a crescer para atender ao aumento da demanda de álcool hidratado, se aproximando de 520 milhões de toneladas em 2007. E mantendo-se em crescimento estável até os dias atuais.

\subsection{Biomassa}

A biomassa é uma matéria-prima atrativa por 3 razões principais: Primeiro, é um recurso renovável, que pode ser de desenvolvimento sustentável no futuro. Segundo, tem propriedades ambientais positivas, resultando em nenhuma liberação de dióxido de carbono e baixo teor de enxofre. E em terceiro lugar, possui um significativo potencial econômico, desde que sua cadeia produtiva apresente custos que possam concorrer com os dos combustíveis fósseis (DEMIRBAS, 2008).

Ushima (2004) afirma que a biomassa pode ser tida como uma fonte natural de energia, pois, armazena a energia solar por meio da reação de fotossíntese, tendo como principais componentes a hemicelulose, a lignina e a celulose (composição média: $\mathrm{C}_{6} \mathrm{H}_{10} \mathrm{O}_{5}$ ), variando pouco, dependendo da natureza da biomassa. Sales, Andrade e Lora (2005) consideram biomassa como sendo todo material de origem orgânica (exemplos: madeira, detritos animais e resíduos orgânicos). Cui e Grace (2008) definem biomassa como uma matéria orgânica, proveniente das plantas, incluindo árvores, culturas agrícolas e outros resíduos.

\subsection{Bagaço da cana-de-açúcar como combustível}

Uma fábrica de açúcar e álcool de cana é autossuficiente em energia. Obtém a potência e calor necessário pela queima de seu próprio combustível, o bagaço. Uma fábrica projetada para ser eficiente em energia e operada adequadamente produzirá excesso de bagaço. O bagaço final, ou simplesmente bagaço, é matéria fibrosa sólida, liberada na saída da última moenda, que após extração do caldo, dispõe-se aproximadamente de $275 \mathrm{~kg}$ de bagaço por tonelada de cana. A composição física do bagaço varia muito pouco, sua propriedade mais importante, sob o ponto de vista da produção do vapor, é sua umidade. Ora um trabalho satisfatório da moenda fornece um bagaço com umidade de $50 \%$ e um trabalho muito bom, ora um bagaço com $45 \%$ de umidade, mesmo com uma moenda muito moderna é difícil chegar a uma umidade menor que $44 \%$, mas os índices mais comuns são de 45 a 50\% de umidade. Além da água, o bagaço contém fibra constituída por celulose e lignina, podendo variar de 12 a 15\%, e materiais em solução na água, consequente da embebição, constituída de açúcares e impurezas (de 2 a 4\%). A composição química do bagaço seco pode variar, mas em média podemos admitir as seguintes composições: Carbono 47\%, Hidrogênio 6,5\%, Oxigênio 44\% e Cinzas 2,5\% (HUGOT, 1977). Com uma fibra normal (12 a 14\%) e uma usina bem equilibrada e concebida, ainda fica um excedente de bagaço (ou de vapor) que pode ser utilizado para outros fins: bombeamento de água de refrigeração, fabricação de subprodutos, destilaria, fornecimento de energia à rede, etc.

O principal item para avaliação de um combustível é o seu poder calorífico, que corresponde ao valor liberado pela combustão de uma quantia unitária de sua massa. Assim 
podemos dizer que seria a quantidade de calorias ou Joules resultante da combustão completa do material por grama ou quilograma. Para os combustíveis que possuem hidrogênio em sua molécula e consequentemente produzem água na combustão (caso do bagaço de cana-deaçúcar), existem dois poderes caloríficos, a saber: Poder Calorífico Superior (PCS), que corresponde ao calor liberado considerando que a água formada está sob a forma líquida a $0^{\circ} \mathrm{C}$ e; Poder Calorífico Inferior (PCI), que corresponde ao calor liberado considerando que a água formada está sob a forma de vapor a $0^{\circ} \mathrm{C}$. A Tabela 1 mostra o PCS de alguns produtos.

Tabela 1 - Poder calorífico superior de alguns produtos.

\begin{tabular}{lc}
\hline Produto & PCS - kcal/kg \\
\hline Lenha (20\% de umidade) & $2500-3000$ \\
Serragem e Cavacos & 2500 \\
Nó de pinho & 4000 \\
Carvão de pedra & 7500 \\
Casca de semente de algodão & 2800 \\
Bagaço de cana de açúcar (40 \% de umidade) & 2300 \\
Álcool etílico & 7200 \\
Butano & 11800 \\
Gasolina & 11000 \\
\hline
\end{tabular}

Fonte: Borges e Lopes (2009)

Segundo Hugot (1977), levando em conta o poder calorífico desses componentes e do teor de umidade do bagaço tem-se: $\mathrm{PCS}=4.600-12 \mathrm{~s}-46 \mathrm{w}$ e PCI $=4.250-12 \mathrm{~s}-48,5 \mathrm{w}$, onde s é o teor de sacarose no bagaço (Pol) e w é teor de umidade em \%. A Tabela 2 mostra a variação do PCI com os teores de umidade e sacarose.

Tabela 2 - PCI do bagaço com diferentes Umidades e Sacarose.

\begin{tabular}{lccccccccc}
\hline Umidade (\%) & 49 & 49 & 49 & 50 & 50 & 50 & 51 & 51 & 51 \\
\hline Pol $\left({ }^{\circ} \mathbf{S}\right)$ & 1 & 2 & 3 & 1 & 2 & 3 & 1 & 2 & 3 \\
PCI - kcal/kg & 1861 & 1850 & 1837 & 1813 & 1801 & 1789 & 1764 & 1752 & 1740 \\
\hline
\end{tabular}

Fonte: Comin (2010)

Segundo Comin (2010), em uma estimativa grosseira, a variação de $1 \%$ na umidade acarreta uma variação de $1 \%$ no valor como combustível. A qualidade do bagaço tem primordial importância e sua umidade constitui o fator mais preponderante. A maioria das caldeiras é projetada para queimar bagaço a $50 \%$ de umidade, dessa forma podem ser esperados problemas na queima do mesmo quando a umidade subir acima de 52\%; desse modo a maior parte do bagaço não seca e não queima em suspensão e se acumula na grelha. No caso de grelha rotativa, isto não é tão problemático, mas, com grelha basculante, o bagaço acumula-se em pilhas e gases combustíveis podem ser gerados, os quais entram em ignição periodicamente, induzindo explosão causando pressão positiva na fornalha. O poder calorífico do bagaço torna-se maior à medida que o teor de umidade se reduz, principalmente devido à menor necessidade de calor para vaporizar a água. O meio mais eficiente de remover a água do bagaço consiste em fazê-lo mecanicamente em uma prensa ou na moenda, mas há um limite mínimo prático. O padrão tradicional para uma moenda de cana é obter um bagaço com $48 \%$ de umidade. No passado, moendas foram operadas com média anual abaixo de $40 \%$, o que seria considerado antieconômico. Atualmente, devido às altas taxas de moagem, o mais baixo valor considerado prático seria entre 45 e $50 \%$ de umidade.

Segundo Morais e Silva (2008), o poder calorífico superior em cada nível de umidade, tem considerável acréscimo com a diminuição da umidade. A Tabela 3 mostra esta relação. 
Tabela 3 - Comparativo do PCS do Bagaço x Umidade.

\begin{tabular}{lccccc}
\hline Poder Calorífico Superior (PCS) & 4360 & 3985 & 3641 & 3145 & 2275 \\
Umidade (\%) & 0 & 10 & 20 & 30 & 40 \\
\hline
\end{tabular}

Fonte: Silva e Morais (2008)

Segundo Santos (2015), o bagaço estocado seco torna-se um combustível mais eficiente. Contudo, também perde rapidamente seu conteúdo de açúcar, o que significa uma perda de energia. Com uma boa extração na moenda, o teor de açúcar residual no bagaço é da ordem de $3 \%$ de energia total disponível. Assim, em períodos curtos de estocagem ( 2 a 3 dias), os efeitos se contrabalançam. Um bagaço com alto teor de açúcar deveria ser queimado de imediato. Convém lembrar, a esse respeito, que com uma extração pobre o bagaço pode mostrar baixo teor de umidade, simplesmente devido a "Pol" elevada.

\subsection{Caldeira}

Caldeiras ou geradores de vapor são os nomes dados aos equipamentos que tem como função mudar o estado da água do líquido para vapor. Outros fluidos podem ser utilizados para produção de vapor, no entanto, a água é preferida, pois possui elevado calor específico e abundância no meio industrial. Os geradores de vapor são comumente utilizados em processos industriais e na geração de energia elétrica (INNOCENTE, 2011).

Para Alves (2002), todos os tipos de caldeiras sempre possuem três partes essenciais, que são: a fornalha ou câmara de combustão, a câmara de água e a câmara de vapor. Os condutos para descarga dos gases e a chaminé não formam parte integral da caldeira, pois constituem construções independentes que são adicionadas ao corpo da mesma, dessa forma não estando expostas à pressão do vapor. Numa unidade termelétrica de cogeração de energia o tipo de caldeira usada é a aquatubular.

De acordo com Martinelli Júnior (1998), as aquatubulares se caracterizam pelos tubos situarem-se fora dos tubulões da caldeira (tambor), constituindo com estes um feixe tubular e diferenciam-se das flamotubulares onde os tubos estão submersos em água. Dessa forma, no interior dos tubos vaporizadores escoam os gases da combustão em direção à chaminé, pois a água circula no exterior dos tubos e os gases quentes estão em contato com sua superfície externa. Assim, operam a média e alta pressão, resultando em alta produção de vapor.

Segundo Torreira (1995), devido sua estrutura interna ser dividida em coletores e tubos de pequeno diâmetro, tem como características: suportarem altas pressões, vaporização específica maior e possuir melhor transmissão de calor em relação às caldeiras flamotubulares. Nas caldeiras aquatubulares a água e o vapor circulam no interior dos tubos vaporizadores, e a superfície externa dos tubos está em contato com os gases da combustão. O rendimento térmico é de 80 a $82 \%$ ou maiores em caldeiras que possuem superaquecedores, economizadores e aquecedores de ar.

\subsection{Cogeração de energia}

O termo "cogeração" é de origem americana e é empregado para designar os processos de produção combinada de energia térmica e potência, mecânica ou elétrica, com o uso da energia liberada por uma mesma fonte primária de combustível, qualquer que seja o ciclo termodinâmico. Um dos aspectos mais importantes, é que o sistema de cogeração é projetado para satisfazer a demanda térmica do consumidor, já que não é viável, na maioria dos casos, comprarem esse tipo de energia de outras empresas. A potência elétrica produzida pode atender parte ou a totalidade das necessidades da própria planta industrial, existindo também a 
possibilidade de produção de excedente de energia elétrica para a venda, constituindo-se em mais um ponto da empresa (FIOMARI, 2004).

Os sistemas de cogeração têm sido bastante incentivados por muitos países, chegando atualmente a representar cerca de $7 \%$ do total de energia produzida mundialmente, e mais de $40 \%$ da energia gerada em alguns países da Europa e EUA. O setor sucroenergético está descobrindo dois novos significados para os produtos resultantes da colheita e do processamento da cana-de-açúcar. Cada muda de cana plantada no país não é mais apenas o início da produção de açúcar e álcool, é também energia elétrica. Antes resíduos de destinação inconveniente, a palha e o bagaço estão se tornando sinônimos de lucro e também de solução para o problema energético (OLIVEIRA, 2014).

Do ponto de vista energético, as usinas sempre produziram um grande volume de bagaço, tornando-se um grande transtorno quanto à disposição desse bagaço na natureza. Diante desse fato, as usinas instalaram ao longo dos anos, modelos que consomem todo esse subproduto sem deixar sobrar nada. Dessa forma, evita-se o consumo de combustíveis externos e se dispõe do bagaço produzido (ZANETTI, 2006).

\section{PROCEDIMENTOS METODOLÓGICOS: coleta das amostras}

As amostras foram obtidas em campo, no período da safra 2018/2019, onde foram coletados os dados da porcentagem da umidade do bagaço por meio da análise do bagaço final pelo laboratório industrial e a produção de energia elétrica gerada pela cogeração.

\subsection{Análise do bagaço pelo método do digestor a frio}

Para executar a análise do bagaço são necessários os materiais relacionados a seguir: balança de precisão, estufa Spencer com cesto, sacarímetro automático, tubo de polarização, agitador magnético, digestor, proveta graduada, béquer, vidro de relógio, funil sem haste, proveta sem graduação, funil de tela, papel de filtro e mistura clarificante. $\mathrm{O}$ procedimento usado para a realização da análise de porcentagem da umidade do bagaço na empresa é pelo método de estufa Spencer (SANTOS, 2015). Onde consiste em pesar 50g do bagaço previamente homogeneizado no cesto da estufa Spencer; ligar a estufa e deixar em funcionamento por $30 \mathrm{~min}$. a $105^{\circ} \mathrm{C}$; desligar, remover o cesto e pesar; recolocar o cesto na estufa Spencer, ligar e deixar em funcionamento por mais $5 \mathrm{~min}$, remover o cesto e tornar a pesar. Se a perda adicional não for maior que $0,1 \mathrm{~g}$ secar por mais $5 \mathrm{~min}$. O que se perde de peso, multiplica por 2 onde indicará a porcentagem de umidade do bagaço.

\subsection{Coleta de dados da umidade do bagaço da cana-de-açúcar na cogeração}

Entre os meses de abril a dezembro do ano de 2018, foram realizadas coletas dos dados de análise do bagaço em umidade, relação vapor/bagaço, relação vapor/MWh bruto, bagaço/MWh bruto, energia bruta, energia líquida e energia líquida exportada. Os valores analisados foram para uma umidade abaixo e acima de $50 \%$, proposta como meta pela cogeração.

\section{RESULTADOS E DISCUSSÃO: análise do bagaço}

A Tabela 4 a seguir, mostra os cálculos e os resultados obtidos em uma análise da umidade do bagaço, as demais seguem o mesmo procedimento. 
Tabela 4 - Resultados de uma análise de porcentagem da umidade do bagaço.

\begin{tabular}{lc}
\hline Massa & Gramas \\
\hline Massa do cesto + amostra em gramas & 300 \\
Massa do cesto + amostra após secagem & 275,8 \\
Diferença de peso em gramas & 24,2 \\
Umidade em \% do bagaço & $24,2 \times 2=48,4$ \\
\hline
\end{tabular}

Fonte: os autores

\subsection{Resultados da coleta de dados da umidade do bagaço na cogeração}

Os resultados apresentados como: umidade, vapor/bagaço, vapor/MWh bruto, bagaço/MWh bruto, energia bruta, energia líquida e energia líquida exportada, foram fornecidos pelo laboratório industrial da usina, entre os meses de abril a dezembro de 2018.

A Tabela 5 mostra, no período de 01/05/2018 a 31/05/2018, os valores para uma umidade abaixo e acima de $50 \%$, proposta como meta pela cogeração.

Tabela 5 - Monitoramento dos dados com umidade abaixo e acima de $50 \%$.

\begin{tabular}{|c|c|c|c|c|c|c|c|}
\hline \multicolumn{6}{|c|}{ CONSUMO ESPECÍFICO $(<50 \%)$} & Usina: UTIB & Mês: MAI/18 \\
\hline \multirow{2}{*}{ Data } & Umidade & $\begin{array}{l}\text { Vapor/ } \\
\text { Bagaço }\end{array}$ & $\begin{array}{c}\text { Vapor/MWh } \\
\text { bruto } \\
\end{array}$ & $\begin{array}{c}\text { Bagaço/ } \\
\text { MWh bruto }\end{array}$ & $\begin{array}{c}\text { Energia } \\
\text { Bruta } \\
\end{array}$ & $\begin{array}{c}\text { Energia } \\
\text { Líquida (EL) }\end{array}$ & $\begin{array}{c}\text { Energ. Líq. } \\
\text { (Exportada) }\end{array}$ \\
\hline & $\%$ & ton/ton & ton/MWh & ton/MWh & $\begin{array}{c}\text { MW } \\
\text { médio/h }\end{array}$ & MW médio/h & MW médio/h \\
\hline $1 / 5 / 18$ & 49,9 & 2,28 & 4,36 & 1,91 & 31,635 & 29,214 & 29,214 \\
\hline $2 / 5 / 18$ & 49,7 & 2,28 & 4,38 & 1,92 & 31,418 & 29,002 & 29,002 \\
\hline $5 / 5 / 18$ & 49,0 & 2,28 & 4,40 & 1,93 & 31,509 & 29,160 & 29,160 \\
\hline $10 / 5 / 18$ & 49,5 & 2,28 & 4,33 & 1,90 & 31,661 & 29,212 & 29,212 \\
\hline $12 / 5 / 18$ & 49,2 & 2,24 & 4,32 & 1,93 & 31,826 & 29,416 & 29,416 \\
\hline $13 / 5 / 18$ & 48,5 & 2,24 & 4,34 & 1,94 & 31,789 & 29,430 & 29,430 \\
\hline $14 / 5 / 18$ & 48,9 & 2,24 & 4,36 & 1,95 & 31,843 & 29,431 & 29,431 \\
\hline $18 / 5 / 18$ & 49,9 & 2,24 & 4,34 & 1,94 & 31,704 & 29,312 & 29,312 \\
\hline Média & 49,33 & 2,26 & 4,35 & 1,93 & 31,67 & 29,27 & 29,27 \\
\hline \multicolumn{6}{|c|}{ CONSUMO ESPECÍFICO $(>50 \%)$} & Usina: UTIB & Mês: MAI/18 \\
\hline \multirow{2}{*}{ Data } & Umidade & $\begin{array}{l}\text { Vapor/ } \\
\text { Bagaço }\end{array}$ & $\begin{array}{c}\text { Vapor/ } \\
\text { MWh bruto }\end{array}$ & $\begin{array}{c}\text { Bagaço/ } \\
\text { MWh bruto }\end{array}$ & $\begin{array}{c}\text { Energia } \\
\text { Bruta } \\
\end{array}$ & $\begin{array}{l}\text { Energia } \\
\text { Líquida } \\
\end{array}$ & $\begin{array}{c}\text { Energ. Líq. } \\
\text { (Exportada) }\end{array}$ \\
\hline & $\%$ & ton/ton & ton/MWh & ton/MWh & $\begin{array}{c}\mathrm{MW} \\
\text { médio/h }\end{array}$ & MW médio/h & MW médio/h \\
\hline $8 / 5 / 18$ & 50,5 & 2,28 & 4,39 & 1,92 & 20,691 & 18,664 & 19,076 \\
\hline $9 / 5 / 18$ & 50,4 & 2,28 & 4,34 & 1,90 & 28,953 & 26,654 & 26,736 \\
\hline $11 / 5 / 18$ & 50,7 & 2,24 & 4,32 & 1,93 & 31,472 & 29,040 & 29,040 \\
\hline $15 / 5 / 18$ & 50,3 & 2,24 & 4,34 & 1,94 & 31,807 & 29,430 & 29,430 \\
\hline $17 / 5 / 18$ & 50,0 & 2,24 & 4,36 & 1,95 & 31,596 & 29,201 & 29,201 \\
\hline $19 / 5 / 18$ & 50,2 & 2,24 & 4,31 & 1,93 & 31,498 & 29,132 & 29,132 \\
\hline $26 / 5 / 18$ & 50,4 & 2,24 & 4,31 & 1,93 & 26,325 & 24,081 & 24,268 \\
\hline $31 / 5 / 18$ & 50,8 & 2,24 & 4,37 & 1,95 & 30,763 & 28,376 & 28,381 \\
\hline Média & 50,41 & 2,25 & 4,34 & 1,93 & 29,14 & 26,82 & 26,91 \\
\hline
\end{tabular}

Fonte: os autores

Conforme a Tabela 5, verificou-se que a média da umidade do bagaço foi de 49,33\%, o qual resultou em uma produção média de energia bruta de 31,67 MW/hora, totalizando 760,08 MW/dia. Verificou-se também que a média da umidade do bagaço está com 50,41\%, o qual resultou um uma produção média de energia bruta de 29,14 MW/hora, totalizando 699,36 MW/dia. Com isso, observou-se que os resultados das análises de umidade do bagaço permaneceram dentro do padrão estabelecido como meta pela usina, porém alguns fatores interferiram para que a umidade não atingisse a meta. É possível que uma das causas tenha sido a pressão hidráulica nos ternos ou a embebição processada na lixiviação. Isso pode ter 
ocasionado uma perda expressiva no consumo de bagaço usado como combustível na caldeira, onde o excedente é aproveitado para gerar energia. Sabe-se que o bagaço com a umidade abaixo de $50 \%$ se consegue atingir uma boa eficiência térmica da caldeira. Na Tabela 6 , tem-se o monitoramento realizado da qualidade da umidade do bagaço no período de 01/07/2018 a 31/07/2018.

Após dois meses de safra, observou-se conforme a Tabela 7, que a média da umidade do bagaço diminuiu em relação ao início da moagem atingindo valores médios de 49,03\%, o qual resultou em uma produção média de energia bruta em 29,39 MW/hora, totalizando 705,36 MW/dia. Na Tabela 8, verificou-se que a média da umidade do bagaço está com 50,29\%, o qual resultou um uma produção média de energia bruta em 28,31 MW/hora, totalizando 679,44 MW/dia.

Tabela 6 - Monitoramento dos dados com umidade abaixo e acima de $50 \%$.

\begin{tabular}{|c|c|c|c|c|c|c|c|}
\hline \multicolumn{6}{|c|}{ CONSUMO ESPECÍFICO $(<50 \%)$} & Usina: UTIB & Mês: JUL/18 \\
\hline \multirow{2}{*}{ Data } & Umidade & $\begin{array}{l}\text { Vapor/ } \\
\text { Bagaço } \\
\end{array}$ & $\begin{array}{c}\text { Vapor/MWh } \\
\text { bruto }\end{array}$ & $\begin{array}{c}\text { Bagaço/MWh } \\
\text { bruto }\end{array}$ & $\begin{array}{c}\text { Energia } \\
\text { Bruta } \\
\end{array}$ & $\begin{array}{l}\text { Energia } \\
\text { Líquida } \\
\end{array}$ & $\begin{array}{l}\text { Energ. Líq. } \\
\text { (Exportada) }\end{array}$ \\
\hline & $\%$ & ton/ton & ton/MWh & ton/MWh & MW médio/h & $\begin{array}{c}\mathrm{MW} \\
\text { médio/h }\end{array}$ & MW médio/h \\
\hline $3 / 7 / 18$ & 49,90 & 2,18 & 4,40 & 2,02 & 28,84 & 26,53 & 26,66 \\
\hline $6 / 7 / 18$ & 49,90 & 2,24 & 4,33 & 1,93 & 30,34 & 29,67 & 29,67 \\
\hline $8 / 7 / 18$ & 49,60 & 2,24 & 4,28 & 1,91 & 30,29 & 29,60 & 29,60 \\
\hline $10 / 7 / 18$ & 49,90 & 2,24 & 4,28 & 1,91 & 26,78 & 26,13 & 26,20 \\
\hline $18 / 7 / 18$ & 48,80 & 2,24 & 4,31 & 1,92 & 30,38 & 29,67 & 29,67 \\
\hline $20 / 7 / 18$ & 47,80 & 2,24 & 4,30 & 1,92 & 27,51 & 26,84 & 26,89 \\
\hline $23 / 7 / 18$ & 48,80 & 2,24 & 4,35 & 1,94 & 30,46 & 29,76 & 29,76 \\
\hline $30 / 7 / 18$ & 48,00 & 2,24 & 4,31 & 1,92 & 30,48 & 29,82 & 29,82 \\
\hline Média & 49,09 & 2,23 & 4,32 & 1,94 & 29,39 & 28,50 & 28,53 \\
\hline \multicolumn{6}{|c|}{ CONSUMO ESPECÍFICO (>50\%) } & Usina: UTIB & Mês: JUL/18 \\
\hline \multirow{2}{*}{ Data } & Umidade & $\begin{array}{l}\text { Vapor/ } \\
\text { Bagaço }\end{array}$ & $\begin{array}{c}\text { Vapor/MWh } \\
\text { bruto }\end{array}$ & $\begin{array}{c}\text { Bagaço/MWh } \\
\text { bruto }\end{array}$ & $\begin{array}{c}\text { Energia } \\
\text { Bruta }\end{array}$ & $\begin{array}{l}\text { Energia } \\
\text { Líquida }\end{array}$ & $\begin{array}{l}\text { Energ. Líq. } \\
\text { (Exportada) }\end{array}$ \\
\hline & $\%$ & ton/ton & ton/MWh & ton/MWh & MW médio/h & $\begin{array}{c}\mathrm{MW} \\
\text { médio/h }\end{array}$ & MW médio/h \\
\hline $1 / 7 / 18$ & 50,20 & 2,24 & 4,41 & 1,97 & 31,86 & 29,52 & 29,52 \\
\hline $2 / 7 / 18$ & 50,10 & 2,18 & 4,39 & 2,02 & 31,82 & 29,48 & 29,48 \\
\hline $7 / 7 / 18$ & 50,50 & 2,24 & 4,32 & 1,93 & 30,26 & 29,59 & 29,59 \\
\hline $9 / 7 / 18$ & 50,20 & 2,24 & 4,36 & 1,95 & 11,06 & 10,37 & 10,80 \\
\hline $11 / 7 / 18$ & 50,70 & 2,24 & 4,26 & 1,90 & 30,21 & 29,59 & 29,59 \\
\hline $13 / 7 / 18$ & 50,20 & 2,24 & 4,30 & 1,92 & 30,30 & 29,64 & 29,64 \\
\hline $24 / 7 / 18$ & 50,20 & 2,24 & 4,33 & 1,93 & 30,49 & 29,79 & 29,79 \\
\hline $26 / 7 / 18$ & 50,20 & 2,24 & 4,32 & 1,93 & 30,44 & 29,74 & 29,74 \\
\hline Média & 50,29 & 2,23 & 4,34 & 1,94 & 28,31 & 27,22 & 27,27 \\
\hline
\end{tabular}

Fonte: os autores

$\mathrm{Na}$ Tabela 7, tem-se o monitoramento realizado da qualidade da umidade do bagaço no período de 01/10/2018 a 30/10/2018.

No mês de outubro, em uma nova coleta de dados do controle de umidade, observou-se um novo cenário como ilustra a Tabela 7 . A umidade do bagaço diminuiu em relação ao mês inicial, porém a produção de energia bruta foi menor. Isso se deve ao fato de o referido mês ter adicionado a palha, juntamente com o bagaço para a queima. Como o poder calorífico superior da palha é bem menor em relação ao bagaço, a eficiência da caldeira diminui, e consequentemente, a produção bruta de energia. 
Tabela 7 - Monitoramento dos dados com umidade abaixo e acima de $50 \%$.

\begin{tabular}{|c|c|c|c|c|c|c|c|}
\hline \multicolumn{6}{|c|}{ CONSUMO ESPECÍFICO-(<50\%) } & \multirow{2}{*}{$\begin{array}{c}\text { Usina: UTIB } \\
\text { Energia } \\
\text { Líquida }\end{array}$} & \multirow{2}{*}{$\begin{array}{c}\text { Mês: OUT/18 } \\
\begin{array}{c}\text { Energ. Líq. } \\
\text { (Exportada) }\end{array}\end{array}$} \\
\hline \multirow{2}{*}{ Data } & Umidade & $\begin{array}{l}\text { Vapor/ } \\
\text { Bagaço }\end{array}$ & $\begin{array}{c}\text { Vapor/MWh } \\
\text { bruto }\end{array}$ & $\begin{array}{c}\text { Bagaço/MWh } \\
\text { bruto }\end{array}$ & $\begin{array}{c}\text { Energia } \\
\text { Bruta }\end{array}$ & & \\
\hline & $\%$ & ton/ton & ton/MWh & ton/MWh & $\begin{array}{c}\mathrm{MW} \\
\text { médio/h }\end{array}$ & $\begin{array}{c}\mathrm{MW} \\
\text { médio/h }\end{array}$ & MW médio/h \\
\hline $1 / 10 / 18$ & 47,20 & 2,24 & 4,31 & 1,93 & 29,303 & 26,678 & 26,827 \\
\hline $6 / 10 / 18$ & 49,90 & 2,24 & 4,31 & 1,92 & 30,331 & 28,976 & 28,976 \\
\hline $9 / 10 / 18$ & 49,60 & 2,24 & 4,33 & 1,93 & 30,774 & 28,316 & 28,316 \\
\hline $11 / 10 / 18$ & 50,00 & 2,24 & 4,33 & 1,93 & 31,111 & 28,428 & 28,428 \\
\hline $16 / 10 / 18$ & 49,40 & 2,24 & 4,38 & 1,95 & 30,490 & 29,701 & 29,701 \\
\hline $21 / 10 / 18$ & 48,40 & 2,24 & 4,38 & 1,96 & 31,075 & 28,431 & 28,431 \\
\hline $28 / 10 / 18$ & 49,70 & 2,24 & 4,36 & 1,95 & 31,298 & 28,585 & 28,585 \\
\hline $30 / 10 / 18$ & 50,00 & 2,24 & 4,34 & 1,94 & 30,377 & 27,517 & 27,517 \\
\hline Média & 49,28 & 2,24 & 4,34 & 1,94 & 30,59 & 28,33 & 28,35 \\
\hline \multicolumn{6}{|c|}{ CONSUMO ESPECÍFICO $(>50 \%)$} & Usina: UTIB & Mês: OUT/18 \\
\hline \multirow{2}{*}{ Data } & Umidade & $\begin{array}{l}\text { Vapor/ } \\
\text { Bagaço }\end{array}$ & $\begin{array}{c}\text { Vapor/MWh } \\
\text { bruto }\end{array}$ & $\begin{array}{c}\text { Bagaço/MWh } \\
\text { bruto }\end{array}$ & $\begin{array}{c}\text { Energia } \\
\text { Bruta }\end{array}$ & $\begin{array}{l}\text { Energia } \\
\text { Líquida }\end{array}$ & $\begin{array}{l}\text { Energ. Líq. } \\
\text { (Exportada) }\end{array}$ \\
\hline & $\%$ & ton/ton & ton/MWh & ton/MWh & $\begin{array}{c}\text { MW } \\
\text { médio/h }\end{array}$ & MW médio/h & MW médio/h \\
\hline $2 / 10 / 18$ & 50,40 & 2,24 & 4,34 & 1,94 & 31,648 & 28,997 & 28,997 \\
\hline $3 / 10 / 18$ & 51,80 & 2,24 & 4,37 & 1,95 & 31,645 & 28,870 & 28,870 \\
\hline $5 / 10 / 18$ & 50,50 & 2,24 & 4,34 & 1,94 & 31,617 & 28,893 & 28,893 \\
\hline $7 / 10 / 18$ & 50,20 & 2,24 & 4,34 & 1,94 & 30,429 & 29,670 & 29,670 \\
\hline $19 / 10 / 18$ & 51,00 & 2,24 & 4,35 & 1,94 & 27,892 & 26,474 & 26,619 \\
\hline $23 / 10 / 18$ & 50,00 & 2,24 & 4,38 & 1,96 & 24,610 & 22,175 & 22,477 \\
\hline $26 / 10 / 18$ & 51,90 & 2,24 & 4,36 & 1,95 & 31,403 & 28,534 & 28,534 \\
\hline $27 / 10 / 18$ & 51,30 & 2,24 & 4,36 & 1,95 & 30,860 & 28,117 & 28,117 \\
\hline Média & 50,89 & 2,24 & 4,36 & 1,94 & 30,01 & 27,72 & 27,77 \\
\hline
\end{tabular}

Fonte: os autores

Observou-se que no mês de maio, início da safra, a umidade do bagaço encontrava-se numa diferença percentual entre a mínima e a máxima de mais de 1,08\%, e com uma pequena variação acima da meta estabelecida. Após dois meses de moagem, e com o controle de umidade sendo realizado três vezes ao dia, observa-se que no mês de julho essa diferença percentual apresentou um pequeno aumento, ficando entre 1,2\%. E no mês de outubro, encerramento de safra, observou-se que a variação de umidade sofreu um pequeno aumento, ficando entre $1,61 \%$, e com a maior variação acima da meta estabelecida. Neste período manteve-se os ajustes da pressão hidráulica dos ternos da moenda e vazão de água, observouse que para ajustar o set point de pressão do $6^{\circ}$ terno, depende do resultado da análise do bagaço, procedimento adotado pela empresa que quando a umidade se altera o seu valor, então eleva-se o set point de pressão. A empresa adota também a prática em utilizar a palha para a queima, juntamente com o bagaço de cana, resultando num teor de umidade mais baixo, porém sem muita eficiência energética na queima. Isso se dá devido ao poder calorífico do palhiço ser menor em relação ao bagaço de cana.

O Gráfico 1 ilustra a produção de energia líquida exportada em MW/dia com a umidade do bagaço abaixo e acima da meta estabelecida pela empresa. No mês de maio a produção de energia com o bagaço abaixo de $50 \%$, resultou numa média de 702,48 MW/dia, ao passo que o bagaço acima da umidade, resultou numa produção média de 645,84 MW/dia. No mês de julho essa produção média ficou em 684,72 MW/dia contra os 654,48 MW/dia com a umidade acima de 50\%. E para finalizar, no mês outubro essa produção ficou em 680,40 MW/dia com a umidade abaixo de 50\% e 666,48 MW/dia com a umidade acima de 50\%. Dessa forma pode-se 
observar que a produção de energia elétrica com o bagaço abaixo da umidade estabelecida como meta pela empresa, possui sem dúvidas, uma venda mais significativa economicamente.

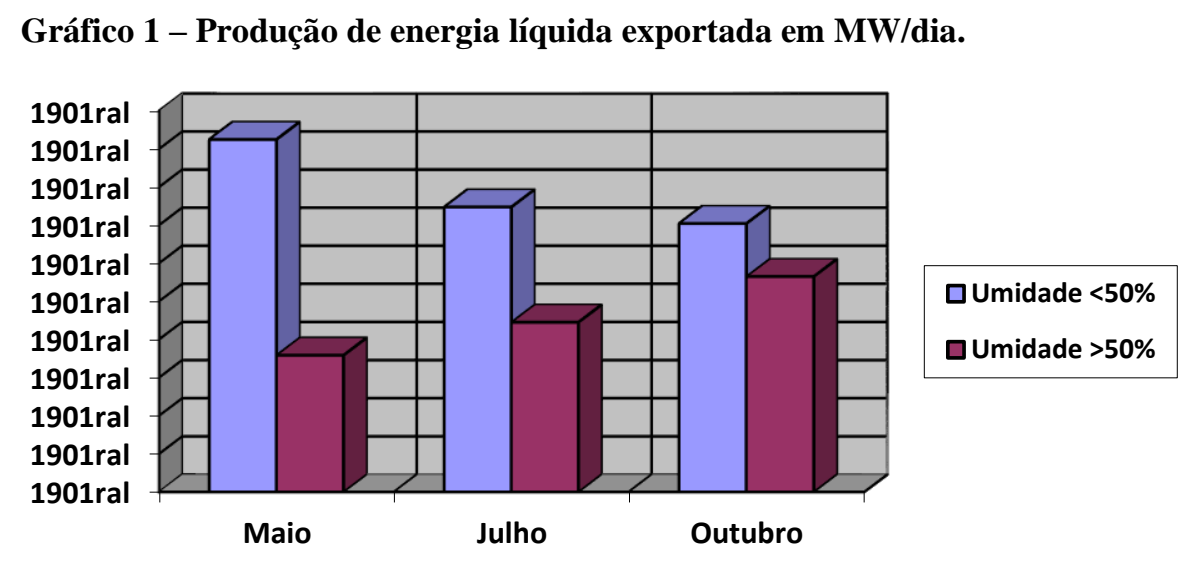

Fonte: os autores

O Gráfico 2 revela a perda de MW/dia convertido em $\mathrm{R} \$$, onde pela perda da eficiência da caldeira devido a umidade do bagaço, houve-se um acréscimo do mesmo para manter a vazão de vapor necessária para o processo e geração de energia elétrica.

Gráfico 2 - Perdas de MW/dia convertido em reais.

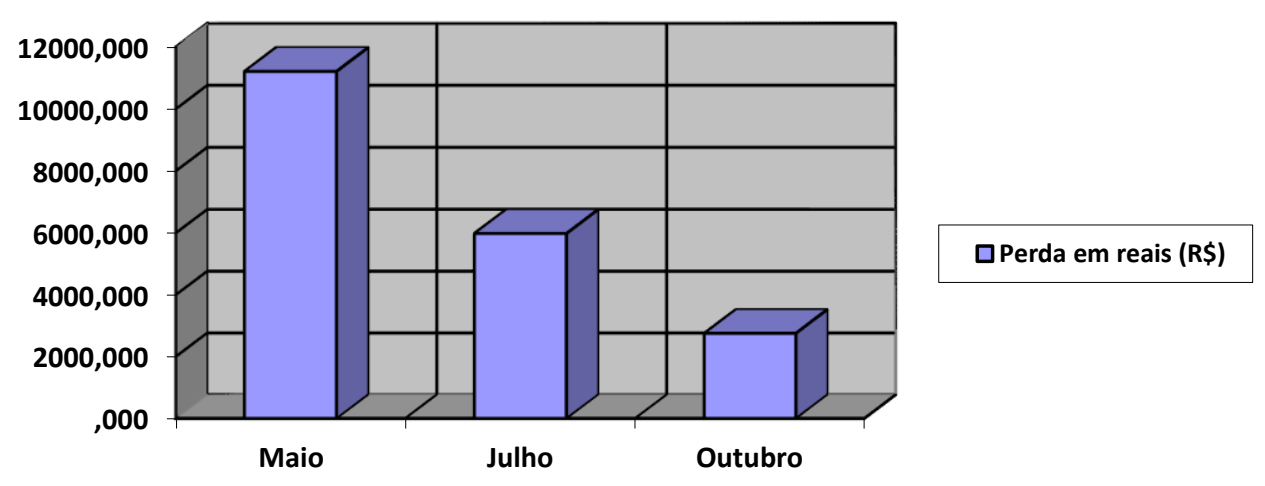

Fonte: Os autores (2018)

O mercado de geração de energia elétrica em valores é determinado pela Câmara de Comercialização de Energia Elétrica (CCEE), mas também pode ser definido pela Agência Nacional de Energia Elétrica (ANEEL), no ano de referência o MWh foi vendido pelo preço fixo de $\mathrm{R} \$ 198,00$, dados fornecidos pela empresa. No mês de maio a perda na geração de energia elétrica devido à umidade do bagaço foi em média de $\mathrm{R} \$ 11.214,72$ por dia. No mês de julho a perda foi em média de $\mathrm{R} \$ 5.987,52$ por dia, e no mês de outubro a perda na geração de energia elétrica resultou-se em média de $\mathrm{R} \$ 2.756,16$ por dia.

\section{CONCLUSÃO}

Para que seja possível a venda de energia elétrica para as concessionárias do governo, as empresas precisam primeiro suprir suas próprias necessidades de consumo de vapor e energia na indústria. Para tanto é necessário que a produção esteja balanceada e dentro de limites 
estabelecidos para que o bagaço e o vapor possam exceder, a fim de produzir energia elétrica e atender a demanda estabelecida pela concessionária.

O parâmetro mais importante como vimos, é o bagaço utilizado na alimentação das caldeiras, e suas características influenciam diretamente no rendimento da produção de vapor. Hora a baixa umidade produz vapor com um consumo menor de bagaço, hora a alta umidade requer um maior consumo para a mesma quantidade produzida, tornando o processo menos eficiente. Além de que, com a baixa umidade, a quantidade de bagaço que sai das moendas é menor, facilitando a armazenagem do excedente. Neste estudo, observou-se ainda que a relação entre a umidade e eficiência é inversamente proporcional, sendo que para o aumento de $1 \%$ na umidade, acarreta aproximadamente na perda de $1 \%$ de eficiência na produção de vapor, e consequentemente na produção de energia. Portanto, as medidas de controle e análise do bagaço final das moendas é de extrema importância nas indústrias de açúcar e álcool, pois, como na prática raramente se mede a quantidade de bagaço consumida pelas caldeiras devido a variação de volume em função da fibra, os cálculos tornam-se fundamentais para mensuração e controle da produção.

Por fim, para a cogeração de energia elétrica, é de suma importância a avaliação e controle de comportamento e rendimento das moendas e consequentemente a qualidade do bagaço que esta fornecerá para o processo em termos de umidade, pois a diminuição do consumo do mesmo pode demandar uma autonomia maior aos turbo geradores e consequentemente maior produção de energia elétrica a ser revendida as concessionárias

\section{REFERÊNCIAS}

ALVES C.S. Sistemas Térmicos: geradores de água quente. Maringá. UEM/Departamento de Engenharia Química, 2002.

BORGES, M. T. M. R; LOPES, C. H. Introdução a Tecnologia Agroindustrial. São Carlos: Eduscar, 2009.

COMIN, M. R. Geração de energia elétrica a partir do bagaço da cana de açúcar. 2010. 48p. Pós-Graduação em Gestão de Tecnologia Industrial Sucroenergética do Departamento de Tecnologia Agroindustrial e Socioeconômica Rural do Centro de Ciências Agrárias da Universidade Federal de São Carlos - Universidade Federal de São Carlos, Araras, 2010.

CUI, H.; GRACE, J. R. Spouting of biomass particles: a review. Bioresourse Technology, England, v. 99, n. 10, p. 4008-4020, July 2008.

DEMIRBAS, A. Biofuels sources, biofuel policy, biofuel economy and global biofuel projections. Energy Conversion and Management, England, v. 49, n. 8, p. 2106-2116, 2008.

FIOMARI, M. C. Análise energética e exergética de uma usina sucroalcooleira do oeste paulista com sistema de cogeração de energia em expansão. 130 p. Dissertação (Mestrado em engenharia mecânica) -Faculdade de Engenharia de Ilha Solteira, Unesp, Ilha Solteira, 2004.

HUGOT, E. Manual da engenharia açucareira. Trad. Hélio Morganti, São Paulo, Mestre Jou, 1977.

INNOCENTE, A. F. Cogeração a partir da biomassa residual de cana-de-açúcar: estudo de caso. Dissertação (Mestrado) - Universidade Estadual Paulista, Faculdade de Ciências Agronômicas. P. 75 a 77, Botucatu, 2011. 
MARTINELLI Jr., L. C. Máquinas Térmicas I: noções sobre geradores de vapor. Cadernos UNIJUÍ, Série Tecnologia Mecânica, nº 8, Editora Unijuí, Ijuí, RS, 1998.

MORAIS, A.S; SILVA, M.B. Avaliação Energética do Bagaço de Cana em Diferentes Níveis de Umidade e Graus de Compactação. Rio de Janeiro: ENEGEP 2008, (Apresentação Realizada XXVIII Encontro Nacional de Engenharia de Produção).

NOVA CANA. A produção de cana-de-açúcar no Brasil (e no mundo). 10 Jan, 2013. Disponível em: http://www.novacana.com/cana/producao-cana-de-açúcar-brasil-e-mundo/. Acesso em: 10 jan. 2019.

OLIVEIRA, A. F. Stella. Avaliação energética da biomassa do bagaço de cana-de-açúcar em diferentes indústrias sucroenergéticas. Dissertação de Mestrado Profissional em Produção - Instituto Tecnológico de Aeronáutica, São José dos Campos. 80 f. 2014.

SALES, C. A. V. B.; ANDRADE, R. V.; LORA, E. E. S. Geração de eletricidade a partir da biomassa. Biomassa e Energia, Viçosa, MG, v. 2, n. 3, p. 195-204, 2005.

SANTOS, C. S. Estudo de caso da eficiência energética na geração de vapor através do uso de bagaço de cana-de-açúcar em uma usina sucroalcooleira no centro oeste mineiro. TCC em Engenharia de Produção do Centro Universitário de Formiga, MG, 2015. 57p.

TORREIRA, R. P. Geradores de vapor. São Paulo: Companhia Melhoramentos, 1995.

USHIMA, A. H. Thermeletric generation system test for remote communities based in the biomass gasification: IPT final report. Hsinchu: Technological Research Institute, 2004.

ZANETTI, A. A.; OLIVEIRA JUNIOR, S. Avaliação comparativa de sistemas de cogeração com utilização de bagaço de cana-de-açúcar e gás natural. Disponível em: http://www.poli.usp.br/d/pme2599/2006/Artigos/Art_TCC_020_2006.pdf. 